\title{
ATTEMPT TO ISOLATE INFECTIOUS AGENT FROM BONE- MARROW OF PATIENTS WITH MULTIPLE SCLEROSIS
}

\author{
William C. Wallen, John L. Sever, Dale E. McFarlin, Henry F. McFarland, Renee G. Traub, \\ Bernard Rentier, JeFFrey I. GreEnStein, PATricia M. MOORE
}

National Institutes of Health, National Institute of Neurological and Communicative Disorders and Stroke, Building 36, Room 5D06, Bethesda, Maryland 20205, U.S.A.

SIR,- - An infectious ætiology for multiple sclerosis (MS) has been postulated but none of the agents putatively associated with the disease have, as yet, been proven to be causative..$^{1-4}$ The reported ${ }^{5}$ isolation of an infectious agent from bone-marrow aspiration of patients with MS prompted us to attempt recovery of an agent from our MS patients.

We studied samples of bone-marrow from 2 male and 5 female MS patients all meeting the accepted criteria for the diagnosis, and five volunteer controls ( 2 men, 3 women, 2 normal, 2 with seizure disorder, and 1 with an emotional problem) kindly obtained with permission of Dr K. Engel and Dr R. Porter of the N.I.H.

Bone-marrow was aspirated into $10 \mathrm{ml}$ Eagle's minimal essential medium (EMEM) containing preservative-free heparin. After washing, the samples were divided into four parts; A for tube cultures,. B for coverslip cultures in multidish wells; C was placed on a 'Ficoll'-'Hypaque' gradient to obtain free mononuclear cells, and D was frozen in liquid nitrogen in cryopreservative medium containing $1 \%$ dimethyl sulphoxide.

CLINICAL STATUS OF MS PATIENTS USED FOR ISOLATION ATTEMPTS

\begin{tabular}{|c|c|c|c|}
\hline $\begin{array}{c}\text { Patient } \\
\text { (Age) }\end{array}$ & $\begin{array}{c}\text { Type of } \\
\text { disease* }\end{array}$ & Category* & CSF-IgG** \\
\hline $1(22)$ & RR & $\mathrm{P}$ & $\mathrm{N}$ \\
\hline $2(32)$ & $\mathrm{RR}$ & $\mathrm{D}$ & + \\
\hline $3(32)$ & $\mathrm{RR}$ & $\mathrm{P}$ & + \\
\hline $4(24)$ & $\mathrm{RR}$ & $\mathrm{D}$ & + \\
\hline $5(34)$ & $\mathrm{RR}$ & $\mathrm{P}$ & \pm \\
\hline $6(39)$ & $\mathrm{RR}$ & $\mathrm{D}$ & + \\
\hline $7(29)$ & $\mathrm{C}$ & $\mathrm{D}$ & + \\
\hline
\end{tabular}

* $\mathrm{RR}=$ recurrent and remitting, $\mathrm{C}=$ chronic; $\mathrm{P}=$ probably $\mathrm{MS}, \mathrm{D}=$ Definite $\mathrm{MS}$

$* * \mathrm{~N}=$ normal, $+=$ elevated $\mathrm{IgG}$ and oligoclonal bands, $\pm=$ borderline elevated $\mathrm{IgG}$ and oligoclonal bands.

After separation of the mononuclear cells, half of sample $\mathrm{C}$ was incubated with $1 \mu \mathrm{g}$ of phytohaemagglutinin for $72 \mathrm{~h}$ to obtain mitogen-activated lymphocytes $\left(\mathrm{C}^{\prime}\right) .0-2 \mathrm{ml}$ samples from A were placed in triplicate in tube cultures. Six replicate multidish plate wells containing cells grown on coverslips were seeded with $0-2 \mathrm{ml}$ aliquots of test cells from groups B, C, and C'. The cell lines employed to rescue the agent included Flow 7000 (a diploid human fibroblast cell line), HEP-2 (transformed human epithelial cells), Vero cells (transformed African green monkey kidney cells), PRK (primary rabbit kidney cells), and three separate lines of Hela cells (a transformed human cervical carcinoma cell line). These were grown initially in EMEM supplemented with $10 \%$ fetal bovine serum (FBS) and 1\% L-glutamine $(200 \mathrm{mmol} / 1)$. Bone-marrow samples were incubated on the monolayer cells for $2 \mathrm{~h}$. The cultures were then fed with a maintenance medium (EMEM with $2 \%$ FBS) and were observed intermittently for two weeks. Fluid containing cells was blindly passaged twice to new tube or 
coverslip cultures containing the corresponding monolayer cells. Each culture was maintained for six to eight weeks before termination. Any cultures showing cytotoxic or cytopathic effects were scraped and transferred to large flasks $\left(150 \mathrm{~cm}^{2}\right)$ containing freshly planted corresponding monolayer cells. These flask cultures were maintained for two additional weeks and then blindly passaged twice. For ultrastructural studies, the cells grown in large flasks were scraped off, centrifuged, and fixed in $4 \%$ cacodylate-buffered glutar-aldehyde. After 120 min, the cells were postfixed in $1 \%$ osmium tetrox-ide, dehydrated with ethanol and embedded. Thin sections were then prepared for electronmicroscopic examination.

No infectious agent was recovered from the bone-marrow samples from either the MS patients or the controls. Samples inoculated directly into tube and coverslip cultures of Vero, Flow 7000, PRK, and HEP-2 showed no cytopathic effect. However, Hela cells inoculated with samples from six of seven MS patients and three of the five controls rapidly formed syncytia within 24 to $48 \mathrm{~h}$ which frequently contained up to 25 nuclei. This happened to two of the three Hela cell lines. Careful re-examination of the three Hela cell lines revealed an occasional syncytium with 3-8 nuclei in the control cultures of two of these cell lines. When fluid and cells from the cultures (showing syncytial formation) with the MS patients and controls were passaged to the Hela cell line not forming spontaneous syncytia, occasional syncytia formed for a short period of time. In each case, the capacity to form syncytia could be passaged. Ultrastructural examination of cultures with syncytium revealed small, spiked, viral-like particles in the Hela cells resembling a foamy virus. No attempt was made to identify this agent further because extensive EM examination of original uninfected cultures revealed a similar type of agent. The passage of fluid from uninoculated control cells spontaneously showing syncytial formation did not enhance this effect in fresh cultures in contrast to the passage from bone-marrow cultures. Direct inoculation of bone-marrow cells from MS or controls on to the third Hela cell line did not result in syncytial formation. Therefore, we believe that a cell-associated syncytial forming agent pre-existed in two of the Hela cell lines and was activated when these cells were cultured with bone-marrow cells from some of the patients or controls.

Mononuclear cells separated from bone-marrow samples by ficoll-hypaque density gradient centrifugation with or without phytohEemagglutinin treatment were seeded at $1 \times 10^{6}$ cells $/ 0-2 \mathrm{ml}$ on to wells of the indicator cell lines in triplicate. Syncytial formation with Hela cells similar to that observed after direct inoculation of bonemarrow was seen but was less frequent. In addition, samples from two of the six MS patients cultured in Vero cells resulted in the formation of small syncytia containing 8-12 nuclei. However, in neither case could transfer of fluid or cells from the affected cultures reproduce this activity nor was any activity noted from any of the,controls.

In the previous investigation reporting the isolation of an infectious agent from MS bone-marrow, the agent(s) could be readily isolated from MS patients (5 of 5) but not from controls ( 0 of 7$){ }^{5}$ Successful isolation was obtained employing MRC-S (human diploid cells), HEP-2, and Vero cells. Lysole-cithin was found to enhance the recovery rate of the agent(s), although it was apparently not necessary for primary isolation. We were unable to isolate an agent from seven MS patients with similar cell lines and procedures. There is no apparent reason for our inability to do so. However, we did find an adventitious agent(s) in two commercial sources of Hela cells. Although not initially apparent, this agent(s) became active upon incubation with either MS-patient or control bone-marrow cells and induced large syncytia when passed to other Hela cells.

\section{References}

1. Brody J, Sever JL, Edgar A, McNew J. Measles antibody titers of multiple sclerosis patients and their siblings. Neurology 1972; 22:492,495-99.

2. Koldovsky U, Koldovsky P, Henle G, et al. Multiple sclerosis associated agent: transmission to animals and some properties of the agent. Infect Immun 1975;12:1355-66.

3. Carp RI, Licursi PC, Merz PA, Merz GS. Decreased percentage of polymor- phonuclear neutrophils in mouse peripheral blood after inoculation with| material from multiple sclerosis patients. $J$ Exp Med 1972; 136: 61S-29.

4. Pertschuck LP, Cook AW, Gupta J. Measles antigen in multiple sclerosis: identification in the jejunum by immunofluorescence. Life Sci 1976; 19: 1603-08.

5. Mitchell DN, Porterfield JS, Micheletti R, et al. Isolation of an infectious agent from bone-marrows of patients with multiple sclerosis. Lancet 1978; ii: 387-90. 